\title{
Pengembangan Three Degree of Freedom Hexapod sebagai Robot Pemadam Api dengan Sensor UVTron Hamamatsu
}

\author{
L. A. Sutawati ${ }^{1}$, I. N. S. Kumara ${ }^{2}$, W. Widiadha ${ }^{3}$
}

\begin{abstract}
The objective of this project is to design and develop an hexapod robot that can locate fire and extinguish it. The design of the robot consists of mechanical or frame, electronics, and software designs. The hexapod robot is a robot with six legs. The legs are driven by servo motors with Three Degree of Freedom (3DOF) to smooth the movement. The servo control uses Torobot 32 Channel servo controller. The fire detection and estinguishing capability are designed using ultrasonic and infrared sensors together with Uvtron sensor. The fire detection system uses Uvtron Hamamats which detects the presence of ultraviolet light through the sensor tube with detection distance up to five meters. The main controller of the robot is Arduino Mega 2560 microcontroller. The algorithm of the robot movement uses wall-following technique to trace the space hence safe path for the robot to move. The robot will move through the room until it locates a fire and then activate the pump to extinguish it, and performs a fire check again. The performance of the robot is tested following typical room simulation as described in the guidelines of Indonesian Robotic Contest.
\end{abstract}

Intisari- Tujuan penelitian ini adalah untuk merancang bangun robot hexapod yang dapat menemukan api serta memadamkannya. Perancangan robot ini meliputi perancangan frame mekanik, perancangan rangkaian elektronika, dan perancangan program. Robot hexapod adalah sebuah robot dengan sistem pengerak berupa kaki sebanyak enam buah. Tiap kaki digerakkan oleh motor servo yang didesain memiliki Three Degree of Freedom untuk memperhalus gerakkan. Sistem servo mengunakan servo kontroler Torobot 32 Channel. Kemampuan pendeteksian dan pemadaman api menggunakan sensor ultrasonik, sensor infrared, dan sensor Uvtron. Sistem pendeteksian api mengunakan sensor Uvtron Hamamatsu yang mendeteksi adanya sinar ultraviolet melalui tabung sensor, dengan jarak pendeteksian sampai dengan 5 meter. Sistem kendali utama menggunakan mikrokontroler Arduino Mega 2560. Algoritma pergerakkan robot mengunakan teknik wallfollowing untuk menelusuri ruangan untuk mendapatkan rute aman bagi robot untuk bergerak. Robot akan bergerak menelusuri ruangan hingga menemukan api dan kemudian menghidupkan pompa air untuk memadamkannya, lalu melakukan pengecekkan api kembali. Unjuk kerja robot ini diuji mengikuti simulasi ruangan yang dijelaskan pada panduan Kontes Robot Indonesia.

Kata Kunci- Robot, hexapod, detektor api, pemadam api, Uvtron Hamamatsu, 3DOF, Degree of Freedom, Arduino

\footnotetext{
${ }^{1}$ Mahasiswa, Jurusan Teknik Elektro, Fakultas Teknik, Universitas Udayana, Jln. Jalan Kampus Bukit Jimbaran 80361 INDONESIA (telp/ fax: 0361-703315; e-mail: ayusutawati@student.unud.ac.id)

${ }^{2}$ Dosen, Jurusan Teknik Elektro Fakultas Teknik Universitas Udayana, Jln. Jalan Kampus Bukit Jimbaran 80361 INDONESIA (telp/ fax:0361-703315; e-mail: satya.kumara@unud..ac.id)

${ }^{3}$ Dosen, Jurusan Teknik Mesin, Fakultas Teknik, Universitas Udayana, Jln. Jalan Kampus Bukit Jimbaran 80361 INDONESIA (telp/fax:0361-703315; e-mail:w.widiadha@unud.ac.id
}

\section{PENDAHULUAN}

Teknologi robot saat ini telah berkembang sangat pesat. Hal ini dapat dilihat dari berbagai penemuan, pengembangan, serta aplikasi robot dalam bidang kehidupan yang makin luas [1] [2] [3]. Peralihan teknologi dari sistem konvensional menjadi sistem atau aplikasi berbasis robot bertujuan untuk meningkatkan efisiensi dan akurasi suatu proses [4]. Robot sudah banyak mengantikan pekerjaan manusia dalam berbagai bidang. Misalnya pengunaan robot lengan pada industri yang membutuhkan akurasi tinggi dan sifat pekerjaan yang berat seperti pada industri kendaraan bermotor. Selain itu, robot juga telah dikembangkan sebagai teman atau mampu berinteraksi dengan manusia secara sosial [3], seperti NAO [5] dan ASIMO [6], yang merupakan robot humanoid yang dilengkapi dengan kecerdasan buatan sehingga dapat berinteraksi dengan manusia layaknya teman.

Robot juga digunakan untuk melakukan pekerjaan yang atau pada lingkungan yang membahayakan manusia [7] [8]. Seperti contoh, Modular Advanced Armed Robotic System (MAARS) yaitu robot perang yang dilengkapi dengan Global Positioning System (GPS) untuk mencari korban luka perang. Robot ini dibuat oleh QinetiQ yang didesain menyerupai bentuk tank untuk menyesuaikan dengan lingkungan aplikasinya [9]. Selain itu juga ada Inuktun robot yang dapat digunakan untuk memantau kebocoran pipa, baik pipa gas maupun air, robot ini dilengkapi dengan body serta sistem yang tahan air.

Kebakaran merupakan salah satu musibah yang sering terjadi di Indonesia yang berdasarkan data Badan Nasional Penanggulangan Bencana (BNPB) di Indonesia selama tahun 2016 telah terjadi 178 kasus kebakaran di wilayah pemukiman. Sementara di Bali, dari Januari hingga Maret 2017 telah terjadi sebanyak 24 kasus kebakaran [10]. Kebakaran pada kawasan pemukiman sering terjadi pada wilayah pertokoan, pasar, atau wilayah padat bangunan lainnya. Hal ini mengakibatkan api menyebar dengan sangat cepat. Sulitnya menemukan serta menjangkau titik api mengakibatkan terhambatnya proses pemadaman, sehingga api dengan cepat menyebar ke bangunan sekitarnya. Daya tahan manusia akan asap kebakaran juga dapat menjadi hambatan dalam proses pemadaman dan dapat membahayakan petugas pemadam. Berbagai penelitian tentang pemadaman api dengan robot telah dilakukan karena potensi kelebihan robot dan tingginya resiko keselamatan bagi petugas pemadam kebakaran [11] [12] [13]. Dengan pengaplikasian teknologi robot maka pencarian titik api akan lebih mudah dilakukan dan lebih aman. Robot juga dapat di rancang untuk menjangkau wilayah yang sulit dijangkau petugas. Serta robot tidak terpengaruh oleh asap dan dengan menggunakan bahan yang tepat maka robot dapat dibuat agar dapat tetap bekerja pada suhu panas akibat api. 
Dari latarbelakang seperti di atas maka pada penelitian ini akan dilakukan rancang bangun robot hexapod dengan tiga derajat kebebasan atau dikenal dengan Three Degree of Freedom (3 DOF) sebagai robot pemadam api dengan mengunakan sensor UVtron Hamamatsu untuk mendeteksi api, sensor infrared dan ultrasonik untuk mempermudah menghindari halangan. Servo Towerpro MG995 sebagai aktuator, Servo Controller Torobot $32 \mathrm{Ch}$ sebagai pengontrol servo. Serta Arduino Mega 2560 mikrokontroler sebagai kendali utama robot. Robot ini akan dikembangkan sesuai dengan sistem peraturan pada Kontes Robot Indonesia Divisi Pemadam Api [14]. Juga akan dilakukan pengujian untuk mengetahui unjuk kerja dari robot yang telah dikembangkan. Beberapa jenis pengujian yang akan dilakukan antara lain pengujian untuk menghindari rintangan, pengujian pendeteksian api, serta pengujian pemadaman api dengan mengunakan pompa air mini.

\section{BAHAN DAN METODE}

\section{A. Bahan dan Komponen}

Bahan dan komponen pembuatan robot Hexapod ini dapat dibagi menjadi dua yaitu bahan atau komponen rangkaian elektronika dan frame robot. Kerangka mekanik robot menggunakan bahan acrylic karena sifatnya yang kuat serta mudah dibentuk. Sementara untuk komponen elektronika yang diperlukan antara lain sensor Ultrasonic, sensor Uvtron, Servo Towerpro MG995, Servo Controller Torobot 32 Ch, dan Sensor Infrared, catu daya, dan Arduino Mega 2560.

\section{B. Langkah pengembangan}

Rancang bangun robot pemadam api ini dilakukan dalam beberapa tahapan, yaitu studi pustaka untuk pengumpulan data serta mengkaji karakteristik dari setiap komponen. Data yang dikumpulkan antara lain karakteristik dari sensor ultrasonik, sensor Uvtron, sensor infrared, Arduino Mega 2560 serta Motor Servo Towepro MG995. Selain itu, dilakukan tinjauan terhadap penelitian sebelumnya mengenai robot hexapod dan robot pemadam api, terutama pada perhitungan desain dari robot hexapod.

Tahap selanjutnya adalah perancangan bodi robot. Pada tahapan ini dirancang desain 3D dari robot hexapod berdasarkan literatur serta hasil penelitian yang dilakukan pada kelompok studi robot Universitas Udayana. Dalam desain diperhitungkan mengenai penempatan titik beban, besar sudut kebebasan tiap kaki, peletakan persendian, penempatan sensor, serta panjang dari coxa, femur dan tibia.

Tahap ketiga merupakan perancangan sistem elektronika. Perancangan elektronika dilakukan dengan menggunakan program Diptrace. Dalam tahap ini dirancang penempatan sensor, rangkaian catu daya, serta rangkaian kontrol. Di samping itu, dilakukan juga perancangan software yang diawali dengan perancangan algoritma. Bahasa pemrograman yang digunakan dalam penelitian ini adalah bahasa $\mathrm{C}$ dengan memanfaatkan Arduino Integrated Development Environment (IDE) sebagai compiler.

Tahap terakhir adalah pengujian yang dilakukan dalam beberapa uji sesuai dengan sistem dan peraturan pada Kontes Robot Indonesia Divisi Pemadam Api (KRPAI). Pengujian yang dilakukan antara lain, pengujian robot saat menemukan halangan hal ini secara efektif akan menguji pembacaan dari sensor ultrasonik dan infrared. Kemudian dilakukan pengujian pendeteksian api, dimana robot akan mencari keberadaan api. Dan terakhir adalah pengujian pemadaman api dengan mengunakan pompa air mini.

\section{PERANCANGAN DAN HASIL}

\section{A. Perancangan Bodi Robot}

Desain dari frame robot ini dirancang agar tidak terlalu membebani motor servo, sehingga beban berat robot masih bisa ditahan servo serta umur servo lebih awet. Pada desain bagian kaki hexapod terdapat bagian yang disebut coxa, femur dan tibia yang merupakan panjang dari pinggul, paha serta tungkai robot. Seperti pada tubuh manusia atau hewan berkaki bagian ini sangat berpengaruh dengan pergerakkan dan keseimbangan dari robot. Pada penelitian ini desain kaki dirancang dengan memiliki tibia yang lebih panjang dari coxa sehingga dimensi robot dapat ditekan menjadi kurang dari 30 $\mathrm{cm}$. Untuk desain femur dibuat sangat pendek agar meringankan beban kerja dari servo kaki, selain itu hal ini juga memungkinkan robot bergerak dengan langkah kecil yang cepat.

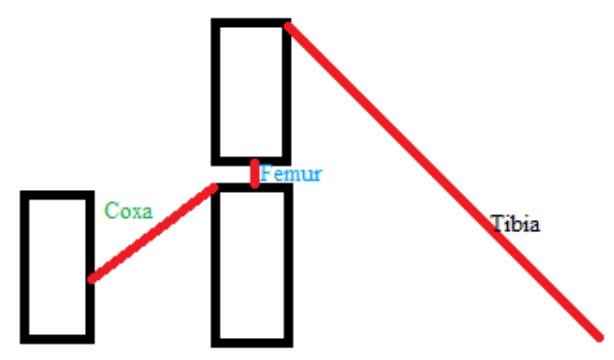

Gambar 1 Desain kaki dan penempatan servo

Setelah desain panjang coxa, femur dan tibia ditentukan kemudian dibuat desain kaki dalam bentuk 3D. Berikut adalah desain 3D dari kaki robot dengan servo lutut dan servo kaki hampir menyatu akibat pendek dari femur.

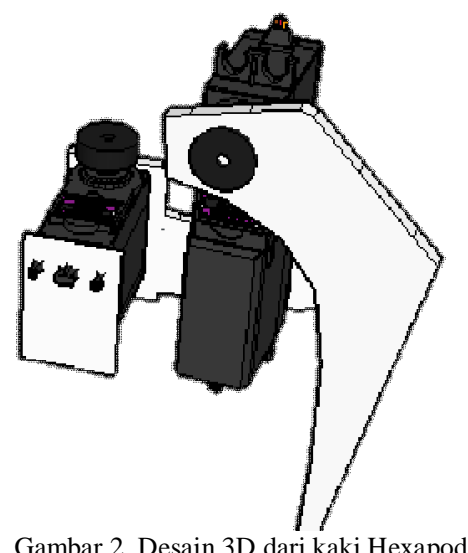

Selanjutkan dilakukan perancangan dari bentuk base robot dan penempatan tiap kaki. Robot ini didesain dengan base berbentuk bulat dengan kaki sejajar. Kaki sejajar ini dimaksudkan dimana tiap kaki dapat berfungsi sebagai bagian depan dari robot. Bahan yang digunakan sebagai frame robot adalah akrilik dengan ketebalan $3 \mathrm{~mm}$. 


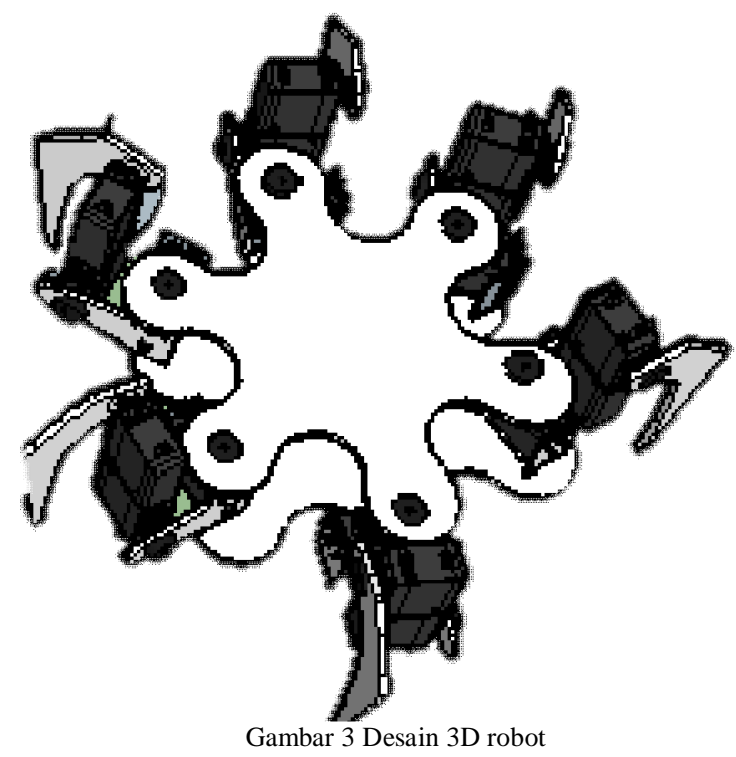

B. Perancangan Elektronika

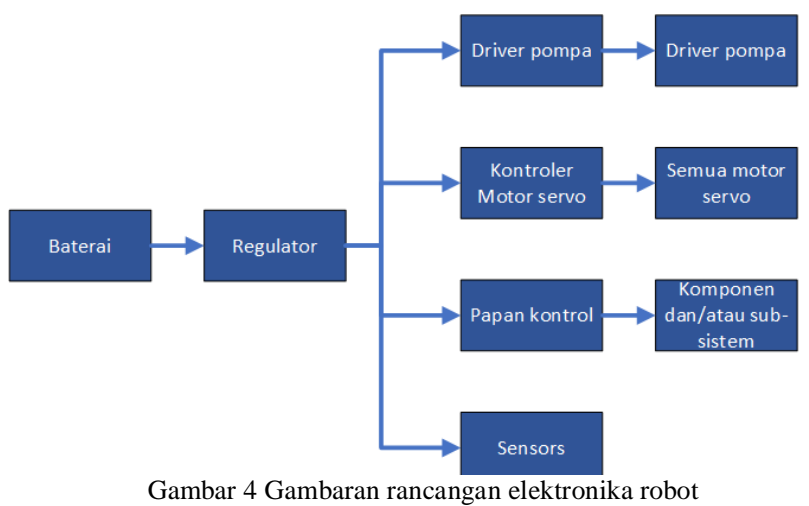

Subsistem elektronika robot terdiri dari beberapa board yang dikelompokkan berdasarkan dengan kegunaannya, seperti ditunjukkan pada Gambar 4. Pemecahan rangkaian robot menjadi beberapa modul atau modular system ini bertujuan untuk mempermudah pengecekan serta faktor keamanan dari komponen.

Robot hexapod ini menggunakan dua buah power supply berupa baterai Lipo 3s $2200 \mathrm{mAh}$ dan Lipo 2s $1500 \mathrm{mAh}$. Power supply Lipo 2s 1500 mAh akan digunakan sebagai catu daya dari rangkaian mikrokontroller Arduino Mega 2560, sensor ultrasonik, dan sensor infrared. Sedangkan catu daya Lipo 3s 2200 mAh digunakan untuk mencatu motor servo dan sensor Uvtron. Selain battery juga digunakan UBEC untuk penstabil arus pada robot. Tegangan input pada masing masing servo sebesar 4,8 volt hingga 6,0 volt. Tegangan ke Arduino Mega 2560 adalah sebesar 5 volt. Dimensi robot yang menyerupai bentuk balok ini memiliki ukuran panjang $\mathrm{x}$ lebar x tinggi: 30 × 30 x $25 \mathrm{~cm}$. Dan berat keseluruhan dari robot adalah sebesar 2,3 $\mathrm{kg}$.

Komponen elektronika yang diperlukan dalam penelitian ini antara lain:

\section{Servo Controller Torobot $32 \mathrm{Ch}$}

Servo Controller merupakan sebuah board yang dapat mempermudah pengontrolan banyak servo secara bersamaan dengan maksimum sebanyak 32 buah servo. Modul ini dilengkapi dengan interface USB dan mendukung dua mode interfacing yaitu USB serta TTL. Pada rangkaian robot hexapod ini board servo controller akan memberikan nilai atau sinyal pulse width modulation (PWM) ke motor servo untuk mengerakkan servo ke posisi yang diinginkan. Rangkaian ini membutuhkan catu daya sebesat 5 volt dan terdapat pin serial untuk menghubungkan dengan Arduino. Pada penelitian ini servo controller akan mendapat perintah dari Arduino untuk nilai PWM atau sudut yang diberikan pada motor servo.

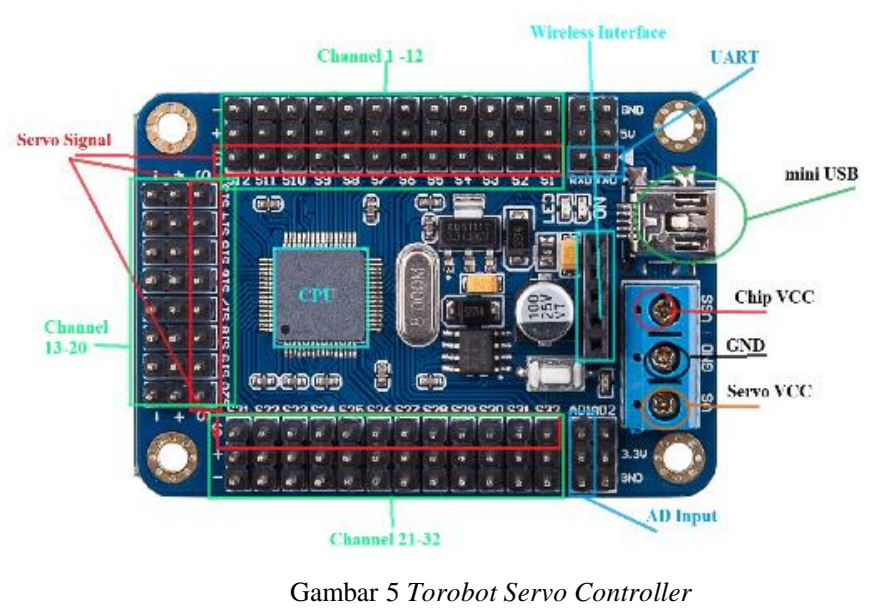

TABEL I

SPESIFIKASI SERVO CONTROLLER [15]

\begin{tabular}{|c|l|l|}
\hline No & \multicolumn{1}{|c|}{ Parameter } & \multicolumn{1}{|c|}{ Nilai } \\
\hline 1 & Logic Power & $\begin{array}{l}+6-12 \text { V or USB power } \\
\text { supply }\end{array}$ \\
\hline 2 & Servo Power Supply & $+4.8-7 \mathrm{~V}$ \\
\hline 3 & Serial Baudrate & $2400,9600,38400,115200$ \\
\hline 4 & EEPROM & $24 \mathrm{C} 2546$ \\
\hline 5 & Speed & $14,75 \mathrm{MHz}$ \\
\hline
\end{tabular}

\section{Arduino Mega 2560}

Arduino Mega 2560 merupakan mikrokontroler yang dikembangkan Arduino dengan mengunakan chip ATMega 2560. Arduino Mega 2560 memiliki 54 pin digital input/ output dimana 12 dari pin tersebut dapat digunakan sebagai output PWM, 16 pin sebagai input analog, 26 pin sebagai input output digital serta 4 pin universal asynchronous receiver and transmitter (UART) untuk komunikasi serial. Perangkat lunak yang digunakan dalam memrogram Arduino Mega 2560 adalah Arduino integrated development environment (IDE). Arduino IDE adalah sebuah platform terpadu untuk melakukan coding, compiling, debuging, dan juga sebagai platform untuk mengunduh executable code ke dalam perangkat Arduino.

Dalam robot hexapod ini Arduino Mega 2560 akan berfungsi sebagai pusat kendali dan operasi data, dimana seluruh data sensor akan diolah pada Arduino untuk kemudian digunakan untuk mengatur servo controller dan juga mengaktifkan sistem pemadam api. 


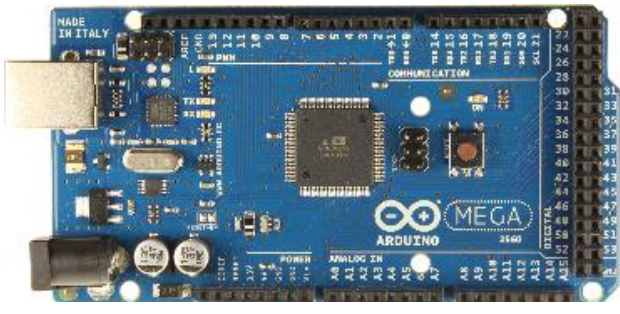

Gambar 6 Arduino Mega2560

\section{Servo TowerPro MG995}

Motor servo merupakan motor yang dirancang untuk pengendalian loop tertutup dimana motor akan bergerak mengikuti perintah sudut atau kecepatan PWM yang diberikan. Motor servo terdiri dari motor DC, rangkaian driver serta gear.

Motor servo TowerPro MG995 merupakan motor servo dengan gear full metal, memiliki torsi 4,8 hingga $9,8 \mathrm{~kg} / \mathrm{cm}$. Motor servo ini memerlukan catu tegangan sebesar 4,6 hingga 5,8 V. Secara lengkap spesifikasi teknis dari servo ditampilkan pada Tabel II.

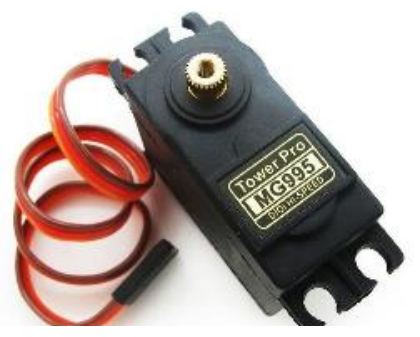

Gambar 7 Servo TowerPro MG995

TABEL II

SPESIFIKASI SERVO TOWERPRO MG995 [17]

\begin{tabular}{|c|l|l|}
\hline No & Parameter & \multicolumn{1}{|c|}{ Nilai } \\
\hline 1 & Speed & $4.8 \mathrm{~V}: 0.20 \mathrm{sec} / 60^{\circ} 6.0 \mathrm{~V}: 0.16 \mathrm{sec} / 60^{\circ}$ \\
\hline 2 & Torque & $\begin{array}{l}4.8 \mathrm{~V}: 9.40 \mathrm{~kg} / \mathrm{cm} \\
6.0 \mathrm{~V}: 11.00 \mathrm{~kg} / \mathrm{cm}\end{array}$ \\
\hline 3 & Weight & $1.94 \mathrm{oz}(55.0 \mathrm{~g})$ \\
\hline 4 & Dimensions & $\begin{array}{l}\text { Length: } 1.60 \mathrm{in}(40.7 \mathrm{~mm}) \text { Width:0.78 in } \\
(19.7 \mathrm{~mm}) \text { Height } 1.69 \mathrm{in}(42.9 \mathrm{~mm})\end{array}$ \\
\hline 5 & Gear Type & Full Metal \\
\hline
\end{tabular}

\section{Sensor Ultrasonik SRF05}

Sensor ultrasonik merupakan salah satu sensor untuk mengukur jarak. Prinsip kerja sensor ini adalah dengan memantulkan gelombang ultrasonik dan menghitung waktu tempuh dari pantulan gelombang ultrasonik yang dipancarkan rangkaian trigger. Untuk mendapatkan nilai jarak dapat dihitung dengan persamaan berikut:

$$
\text { jarak = kecepatan suara } x \text { waktu } \frac{\text { pantul }}{2}
$$

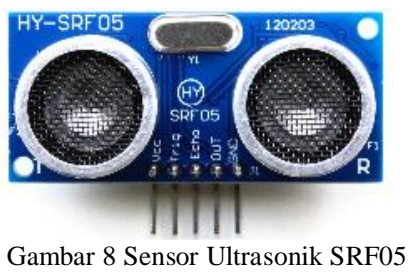

TABEL III

SPESIFIKASI SRF05

\begin{tabular}{|c|c|c|}
\hline No & Parameter & Nilai \\
\hline 1 & Supply Voltage & $4.5 \mathrm{~V}$ to $5.5 \mathrm{~V}$ \\
\hline 2 & Supply Current & 10 to $40 \mathrm{~mA}$ \\
\hline 3 & Measurement Rate & $40 \mathrm{~Hz}$ \\
\hline 4 & Measurement Range & $2 \mathrm{~cm}$ to $4.5 \mathrm{~cm}$ \\
\hline 5 & Measurement Resolution & $0.3 \mathrm{~cm}$ \\
\hline 6 & Sound Frequency & $40 \mathrm{kHz}$ \\
\hline 7 & Dimensi & $\begin{array}{llll}43 \mathrm{~mm} & \mathrm{x} & 20 \mathrm{~mm} & \mathrm{x} \\
17 \mathrm{~mm} & & & \\
\end{array}$ \\
\hline
\end{tabular}

\section{Sensor Uvtron Hamamatsu}

Sensor Uvtron merupakan salah satu sensor pendeteksi api. Sensor ini terdiri dari tabung Uvtron yang berfungsi untuk mendeteksi adanya radiasi cahaya ultraviolet. Cahaya ultraviolet merupakan salah satu komponen dari nyala api. Cahaya ini tidak dapat dihasilkan oleh cahaya lampu biasa sehingga akurasi pada pendeteksian lebih baik.

Sensor ini terdiri dari dua bagian yaitu bagian tabung yang disebut Uvtron yang dapat mendeteksi sinar ultraviolet serta bagian rangkaian atau yang disebut driver. Rangkaian driver merupakan bagian yang memberikan power supply pada tabung dan mengolah data Analog to Digital Converter (ADC). Driver ini terhubung pada pin digital dari Arduino Mega 2560.

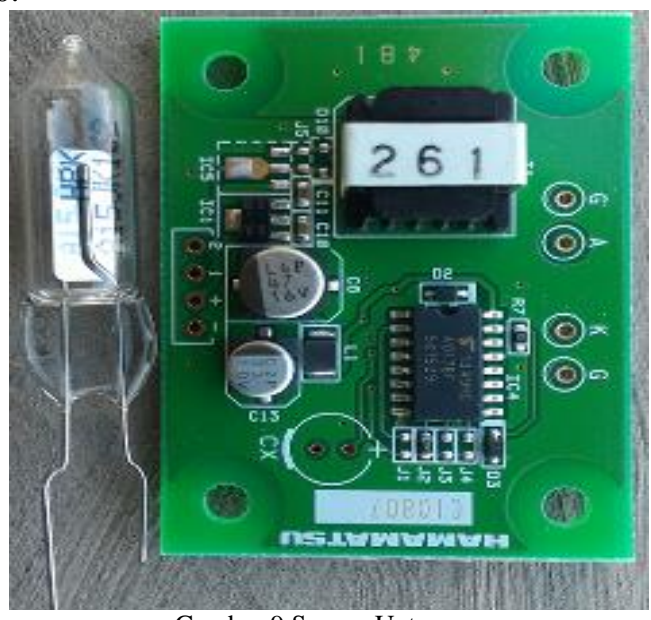

Gambar 9 Sensor Uvtron

TABEL IV

SPESIFIKASI UVTRON HAMAMATSU

\begin{tabular}{|c|l|l|}
\hline No & \multicolumn{1}{|c|}{ Parameter } & \multicolumn{1}{c|}{ Nilai } \\
\hline 1 & Electrode Material & $\mathrm{Ni}$ \\
\hline 2 & Spectral Response (Short) & $185 \mathrm{~nm}$ \\
\hline 3 & Spectral Response (Long) & $2 \mathrm{~cm}$ to $4.5 \mathrm{~m}$ \\
\hline 4 & Weight & $1.5 \mathrm{~g}$ \\
\hline 5 & Average Life & $10000 \mathrm{~h}$ \\
\hline
\end{tabular}


1. Sensor Infrared GP2Y0A02YK0F

Sensor infrared GP2Y0A02YK0F menghasilkan pembacaan analog yang akan mendeteksi jarak berdasarkan waktu pemantulan cahaya infrared yang ditembakkan. Prinsip kerja dari sensor ini menyerupai prinsip kerja sensor ultrasonik, namun data yang dipancarkan berupa sinar infrared. Dibandingkan dengan sensor ultrasonik, sensor ini memiliki pembacaan yang lebih baik pada halangan yang tidak padat atau tidak rata.

TABEL V

SPESIFIKASI SENSOR INFRARED GP2Y0A02YK0F

\begin{tabular}{|c|l|l|}
\hline No & \multicolumn{1}{|c|}{ Parameter } & \multicolumn{1}{|c|}{ Nilai } \\
\hline 1 & Detection Range & $20-150 \mathrm{~cm}$ \\
\hline 2 & Voltage & 4 sampai $5.5 \mathrm{~V}$ \\
\hline 3 & Current & $33-50 \mathrm{Ma}$ \\
\hline
\end{tabular}

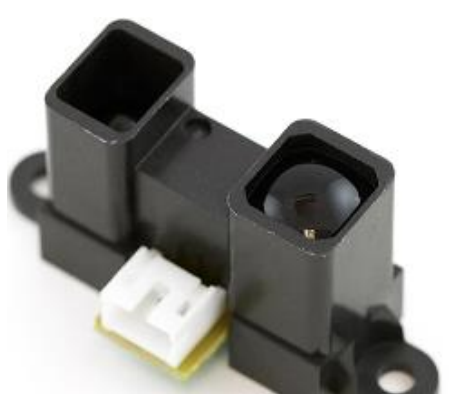

Gambar 10 Sensor Infrared GP2Y0A02YK0F

\section{Pompa air mini}

Pompa ini berfungsi untuk memadamkan api setelah robot menemukan sumber api. Pompa ini adalah pompa air DC dengan tegangan sebesar 12 Volt. Pompa memiliki tabung yang membawa cairan kurang lebih 100 mililiter.

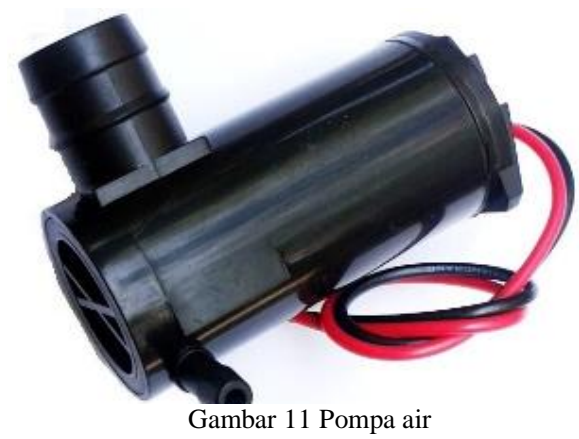

TABEL VI

SPESIFIKASI POMPA AIR MINI

\begin{tabular}{|c|l|l|}
\hline No & Parameter & \multicolumn{1}{|c|}{ Nilai } \\
\hline 1 & Voltage & DC 6-12 V \\
\hline 2 & Current & 2 A \\
\hline 3 & Pump Rate & 3L/menit \\
\hline 4 & Connection & 2 wire \\
\hline
\end{tabular}

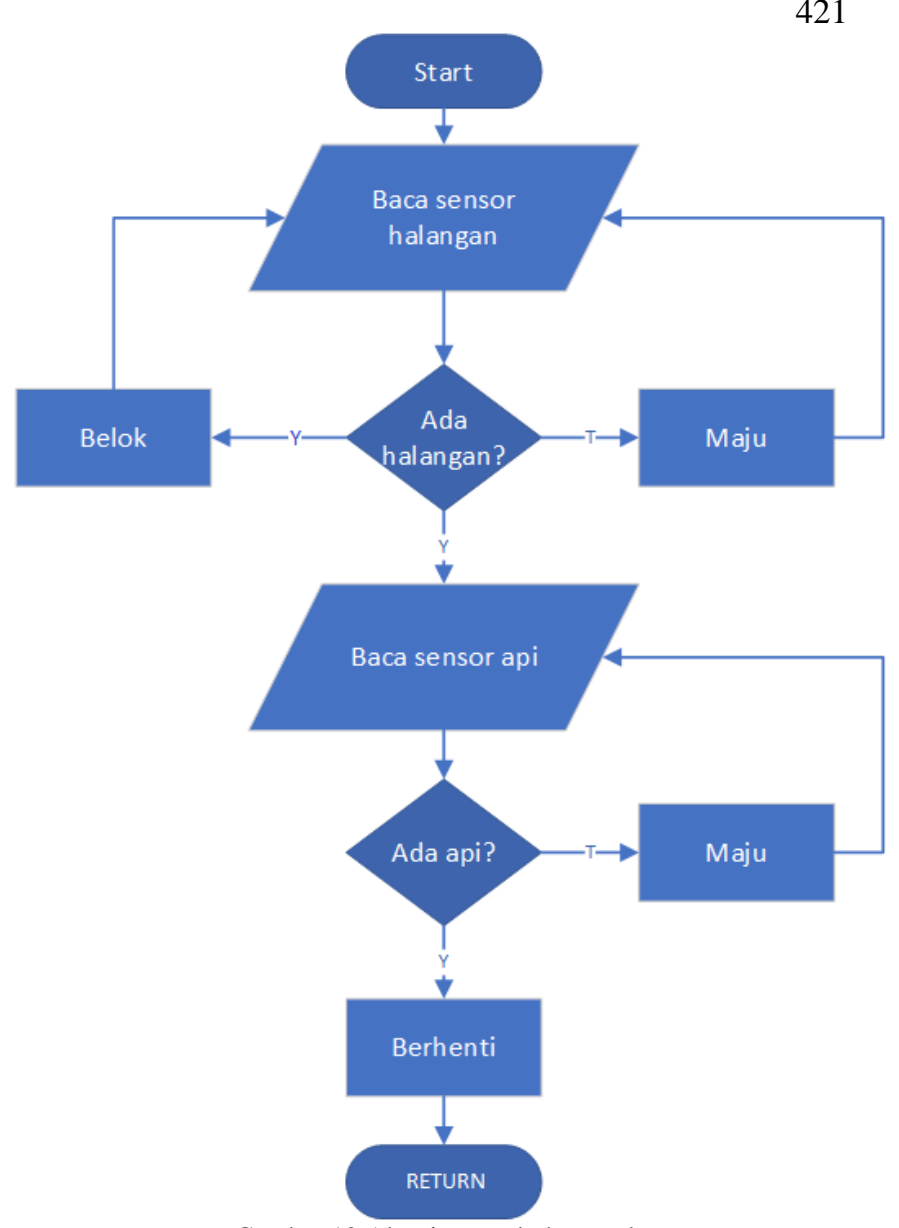

Gambar 12 Algoritma sederhana robot

Pada sistem pergerakkan dari robot ini digunakan algorithma wall-following, yang merupakan suatu algoritma yang menyediakan orientasi navigasi robot dengan cara menelusuri dinding. Dengan algoritma ini robot akan bergerak menelusuri ruangan dengan tetap menjaga jarak robot ke dinding di sekitar. Penentuan jarak robot dari dinding dilakukan dengan mengunakan sensor ultrasonik dan infrared. Untuk menjaga posisi robot dengan dinding, dilakukan perbandingan antara jarak dinding kanan dan kiri. Perbandingan ini dilakukan dengan mengunakan data dari sensor ultrasonik yang dipasang pada sudut 45 derajat. Metode pergerakkan ini memungkinkan robot berada di tengah lorong.

Posisi robot pada lorong sangat menentukan arah pergerakkan robot saat mencari ruangan, karena itu algoritma wall-following merupakan komponen wajib dalam robot hexapod pemadam api ini [18].

Logika wall-following ini digabungkan dengan logika telusur kiri, dengan begitu robot akan lebih memilih menelusuri ruangan di sisi kiri. Hal ini bertujuan untuk mencegah robot berputar - putar pada ruangan yang sama.

\section{Perancangan Algoritma}

L.A. Sutawati Pengembangan Three Degree of (...) 


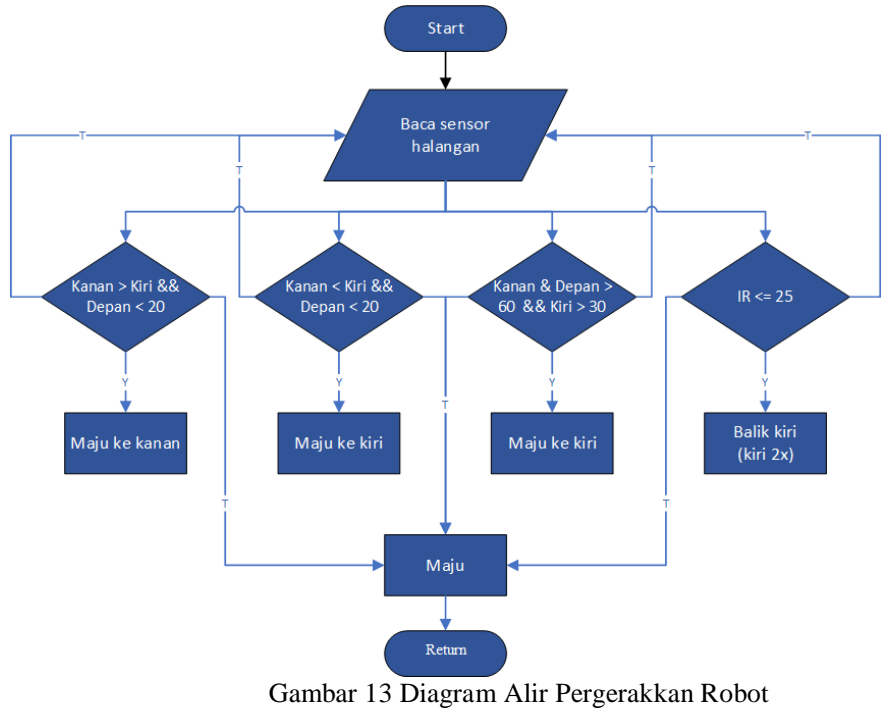

Pada kontrol pergerakkan robot, Arduino Mega 2560 akan mengolah nilai dari sensor ultrasonik dan infrared kemudian akan membuat sebuah keputusan tentang arah pergerakkan dari robot. Perintah gerakan robot ini akan dikirim oleh Arduino menuju Servo Controller. Komunikasi ini dilakukan secara komunikasi serial. Setelah itu, Servo Controller akan mengirimkan sinyal tentang arah pergerakan robot ke setiap servo pada robot.

Pencarian dan pemadaman api akan dilakukan dengan membaca nilai dari sensor Uvtron. Jika api terdeteksi maka robot akan berada pada posisi standby atau berhenti yang diikuti dengan perintah penyalaan pompa air mini untuk memadamkan api. Setelah beberapa saat, robot kembali melakukan pembacaan sensor guna memastikan bahwa api sudah padam. Bisa dilihat dari Gambar 15 yang menunjukan flowchart dari program pencarian serta pemadaman api. Pertama sensor akan membaca nilai sensor Uvtron dengan terus menerus. Saat tidak ada api maka robot akan bergerak sesuai dengan algoritma pergerakan, yaitu wall-following dan telusur ruangan. Saat sensor mendeteksi api robot akan langsung berhenti dan berada dalam posisi standby setelah itu robot akan menyalakan pompa air untuk memadamkan api. Pompa air akan menyala selama 1 menit, setelah itu sensor akan melakukan pembacaan ulang untuk memasikan api sudah padam. Jika api ternyata belum pada maka pompa air akan dihidupkan lagi selama 1 menit untuk memadamkan api. Setelah api sudah benar - benar padam robot akan kembali bergerak berdasarkan algoritma pergerakkan.

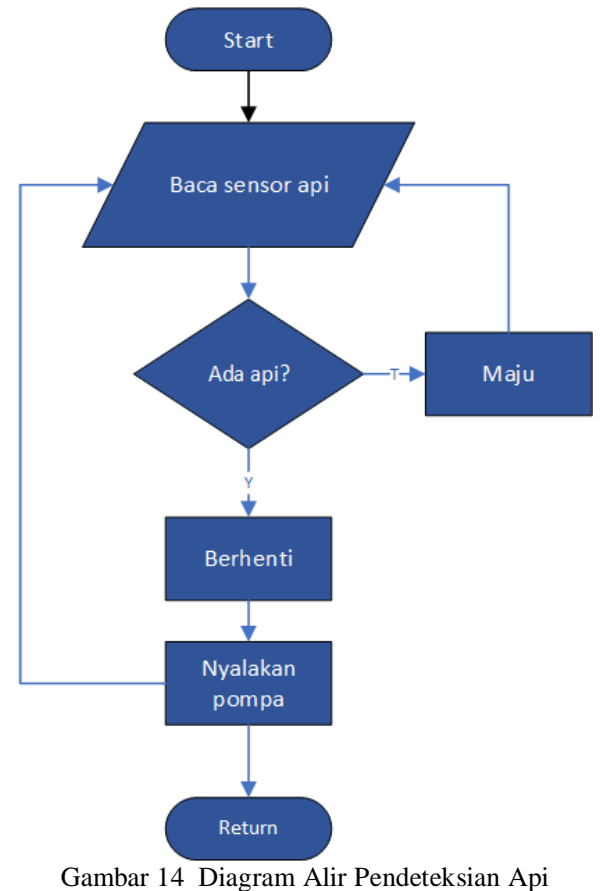

Dalam pembuatan program atau coding mengunakan Arduino integrated development environment yang merupakan compiler resmi dari Arduino. Arduino IDE ini bisa diunduh pada situs resmi Arduino. Tahap awal dari pengembagan program adalah membuat source code yang diketik/ dibuat dalam Arduino IDE. Setelah code dibuat berdasarkan algoritma maka dilanjutkan dengan proses kompilasi atau compile. Setelah hasil kompilasi ini sempurna atau error free maka tahap terakhir adalah mengunggah hasil kompilasi ke dalam Arduino.

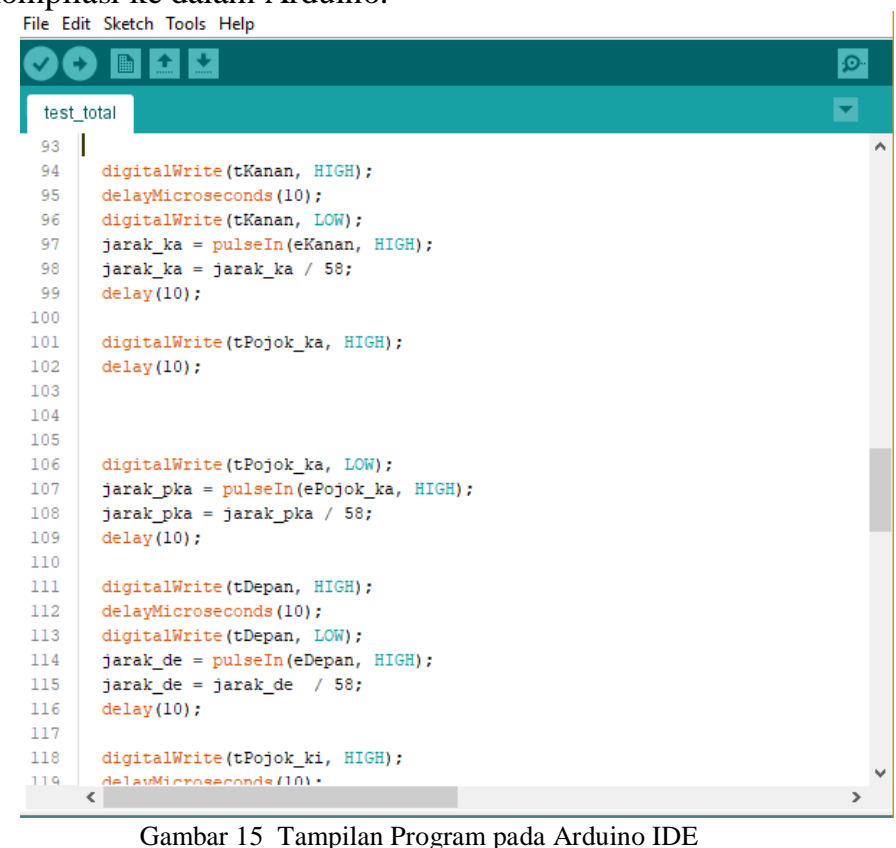

\section{Skematik Sistem Kerja Robot}

Sistem kerja robot ini mengunakan dua sistem kontrol, yaitu Arduino Mega 2560 sebagai pusat kontrol dan Servo Controller untuk mengendalikan servo. Servo Controller 
Majalah Ilmiah Teknologi Elektro, Vol. 17, No. 3, September - Desember 2018

DOI: https://doi.org/10.24843/MITE.2018.v17i03.P17

akan bertindak sebagai slave dari Arduino Mega 2560 yang perintahnya akan dikirim secara komunikasi serial. Untuk catu daya digunakan dua catu daya, yaitu catu daya 12 volt untuk sumber tegangan motor servo serta sensor Uvtron dan catu daya 5 volt untuk mikrokontroler serta sensor ultrasonik dan infrared. Untuk lebih jelasnya skematik sistem kerja dari robot ditunjukkan pada diagram blok pada Gambar 17.

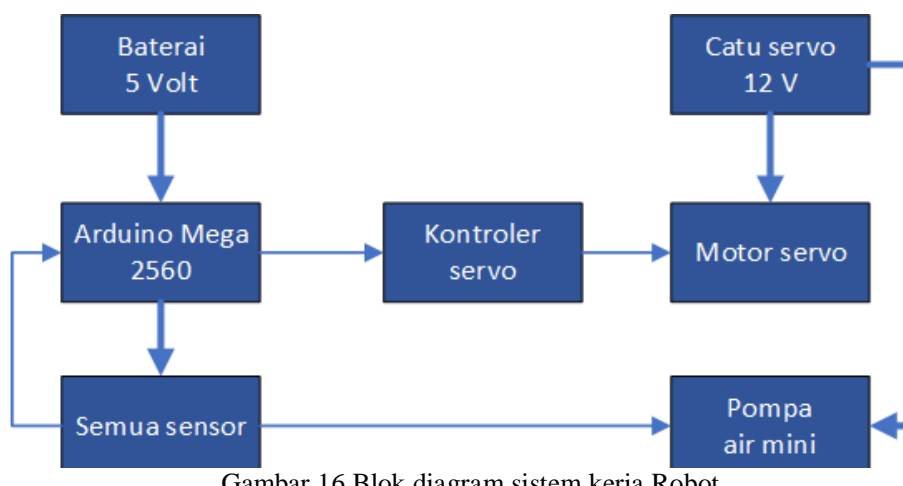

Pengunaan dua sistem kontrol terpisah untuk motor servo dari robot bertujuan agar gerakkan masing - masing servo dapat lebih sinkron, serta agar pemakaian pin pada Arduino Mega 2560 dapat dikurangi.

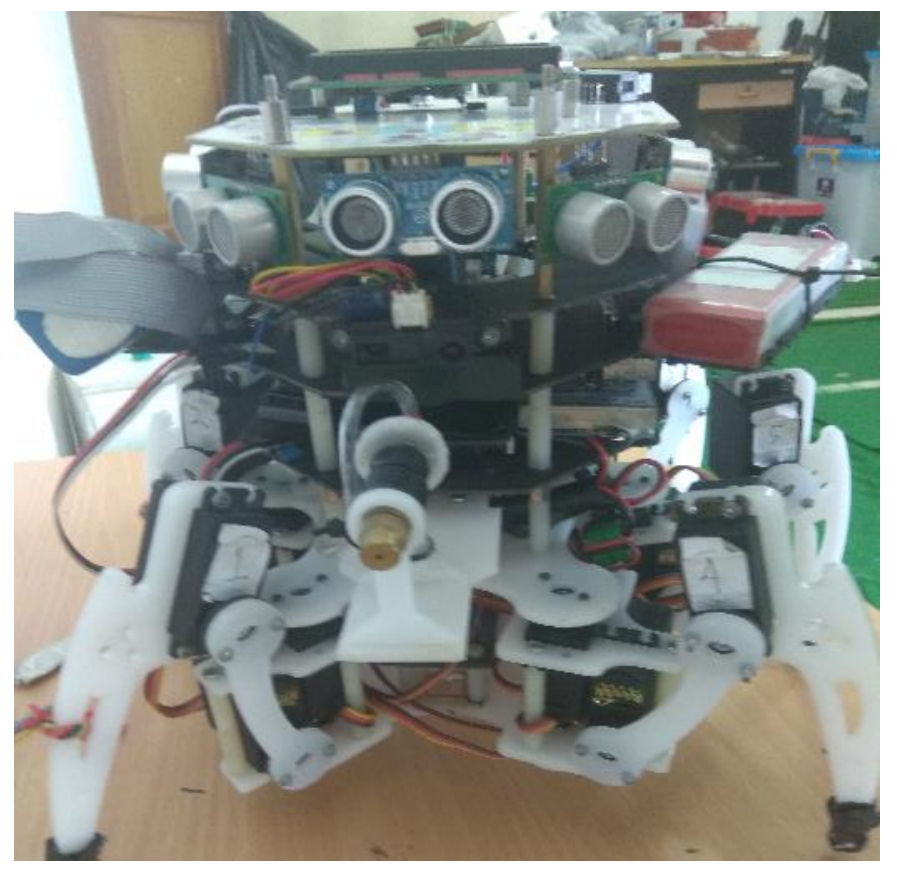

Gambar 17 Robot Hexapod 3 DOF

\section{E. Pengujian Robot}

Pengujian pada robot dilakukan pada model salah satu lintasan dari Kontes Robot Indonesia Divisi Pemadam tahun 2017. Pada lintasan pengujian terdapat 4 buah room atau ruangan, sebuah boneka, dan sebuah lilin. Posisi dari masing masing benda ini pada tiap percobaan akan ditaruh secara acak.

Lintasan yang digunakan terbuat dari papan kayu dengan warna dasar putih, dan di beberapa bagian lintasan dipasang

L.A. Sutawati Pengembangan Three Degree of (...) karpet berwarna abu - abu. Karpet ini berfungsi mengurangi beban robot karena lintasan yang licin. Untuk penanda tiap ruangan terdapat garis putih dengan tebal $5 \mathrm{~cm}$.

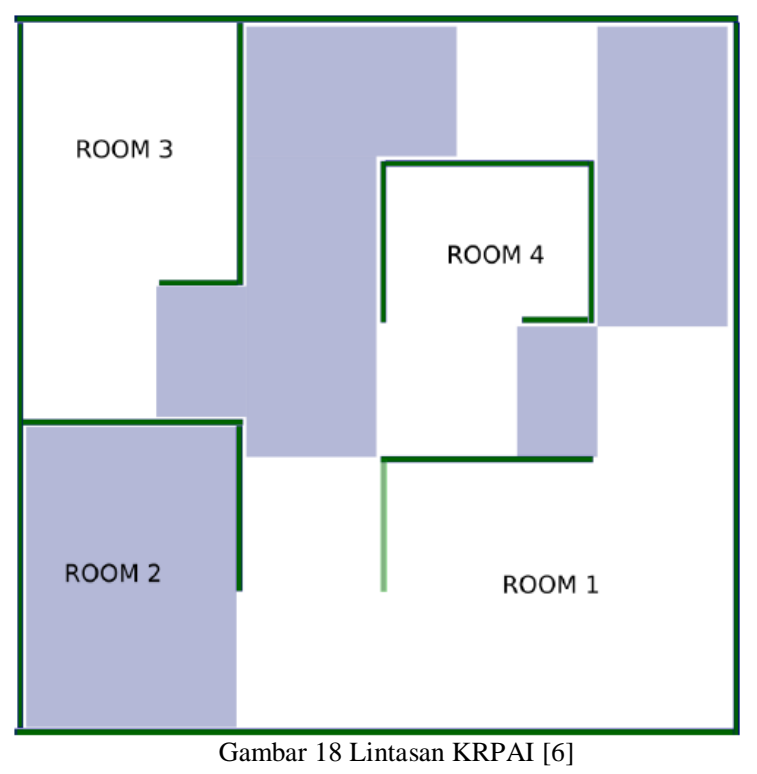

\section{IV.PENGUJIAN}

Pada pengujian mengunakan lintasan seperti Gambar 18 ditujukan dengan Gambar 19 serta Gambar 20.

\section{Pengujian Pendeteksian Halangan}

Ketika robot berada pada lorong, maka robot bergerak sesuai dengan logika wall-following, yaitu menelusuri lorong tersebut dan pada saat menemukan percabangan maka robot akan mengunakan logika telusur kiri untuk memasuki dan keluar dari ruangan.

Saat jarak dinding depan dan kanan terdeteksi oleh sensor Ultrasonik kurang dari $25 \mathrm{~cm}$, maka robot bergerak ke arah kanan begitu pula sebaliknya. Saat jarak antara sensor Ultrasonik pojok kanan lebih besar dari jarak sensor ultrasonik pojok kiri robot bergerak kekiri dan sebaliknya. Jika robot menemukan percabangan maka robot berbelok ke arah kiri. Namun saat infrared mendeteksi halangan maka robot melakukan belok ke kiri sebanyak dua kali.

Pada saat robot pertama dihidupkan robot dilakukan pembacaan nilai sensor - sensor, jika tidak terdapat halangan atau dinding robot bergerak maju. Pada saat robot mendeteksi halangan dengan jarak $25 \mathrm{~cm}$, Arduino kemudian memberikan perintah robot untuk berbelok ke arah yang memiliki jarak lebih jauh.

TABEL VII

PENGUJIAN PERGERAKKAN ROBOT TERHADAP NILAI SRF

\begin{tabular}{|c|c|c|c|c|c|}
\hline Kiri & $\begin{array}{c}\text { Pojok } \\
\text { Kiri }\end{array}$ & Depan & $\begin{array}{c}\text { Pojok } \\
\text { Kanan }\end{array}$ & $\begin{array}{c}\text { Kana } \\
\text { n }\end{array}$ & Pergerakkan \\
\hline $11 \mathrm{~cm}$ & $14 \mathrm{~cm}$ & $45 \mathrm{~cm}$ & $13 \mathrm{~cm}$ & $10 \mathrm{~cm}$ & Maju \\
\hline $32 \mathrm{~cm}$ & $15 \mathrm{~cm}$ & $15 \mathrm{~cm}$ & $18 \mathrm{~cm}$ & $40 \mathrm{~cm}$ & Kiri \\
\hline $13 \mathrm{~cm}$ & $18 \mathrm{~cm}$ & $27 \mathrm{~cm}$ & $29 \mathrm{~cm}$ & $32 \mathrm{~cm}$ & Maju \\
\hline $13 \mathrm{~cm}$ & $18 \mathrm{~cm}$ & $23 \mathrm{~cm}$ & $27 \mathrm{~cm}$ & $32 \mathrm{~cm}$ & Kanan \\
\hline $19 \mathrm{~cm}$ & $24 \mathrm{~cm}$ & $16 \mathrm{~cm}$ & $38 \mathrm{~cm}$ & $41 \mathrm{~cm}$ & Kanan \\
\hline $34 \mathrm{~cm}$ & $26 \mathrm{~cm}$ & $15 \mathrm{~cm}$ & $26 \mathrm{~cm}$ & $42 \mathrm{~cm}$ & Kanan \\
\hline
\end{tabular}


Pada Tabel VII terlihat saat nilai sensor SRF depan lebih dari $25 \mathrm{~cm}$ maka robot bergerak maju. Saat nilai SRF depan lebih kecil dari $25 \mathrm{~cm}$ dan jarak SRF kanan dan kiri masing masing lebih dari $25 \mathrm{~cm}$ maka robot bergerak ke kiri, hal ini dikarenakan algoritma pada robot yang mengunakkan telusur kiri sehingga robot akan lebih mengutamakan pergerakkan ke kiri. Tapi saat jarak SRF depan dan kiri dibawah $25 \mathrm{~cm}$ robot bergerak ke arah kanan, pengunakan telusur kiri ini untuk mempermudah robot dalam menelusuri semua ruangan tanpa terjebak pada satu ruangan yang sama.

Berikut adalah Gambar pengujian sensor ultrasonik dan infrared pada robot dengan dinding berada didepan robot, dan jarak kanan robot kurang dari $25 \mathrm{~cm}$.

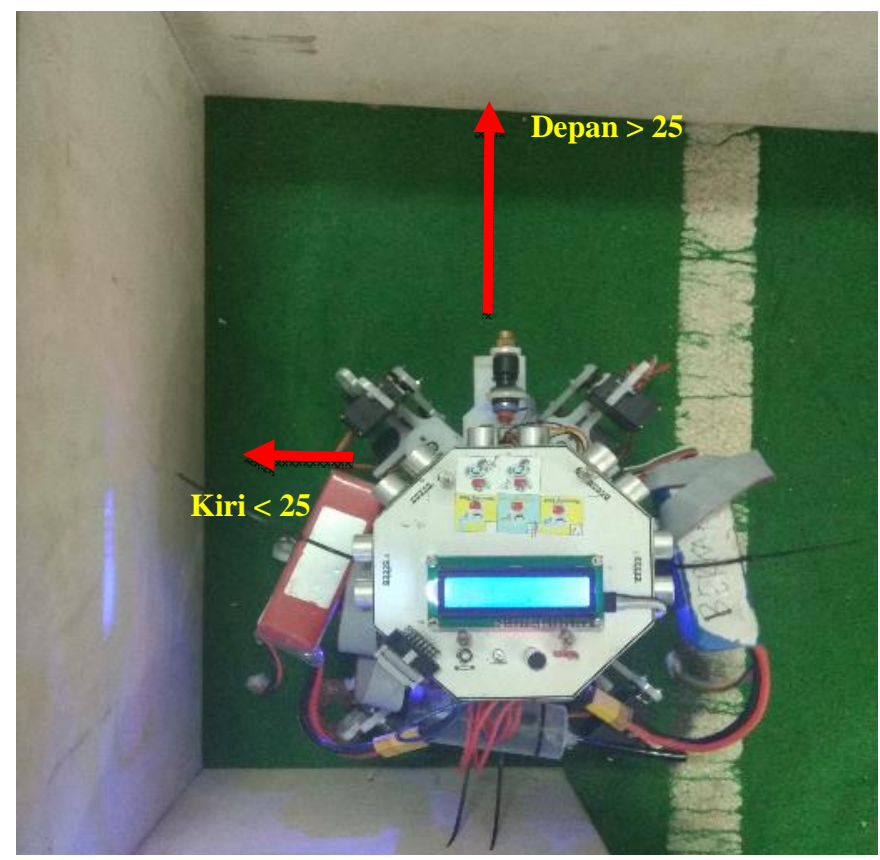

Gambar 19 Robot sebelum mendeteksi halangan

Saat tidak terdapat rintangan atau api robot bergerak ke arah depan atau maju. Kemudian saat sensor pembacaan sensor Ultrasonik dan sensor Infrared kurang dari $25 \mathrm{~cm}$ akan dianggap terdapat halangan maka robot bergerak sesuai dengan kondisi serta logika telusur pada robot. Pada Gambar 19 terlihat robot belum mendeteksi halangan sehingga robot bergerak kedepan, pada Gambar 20 robot mendeteksi adanya halangan didepan serta disebelah kiri, maka robot berbelok ke sisi kanan.

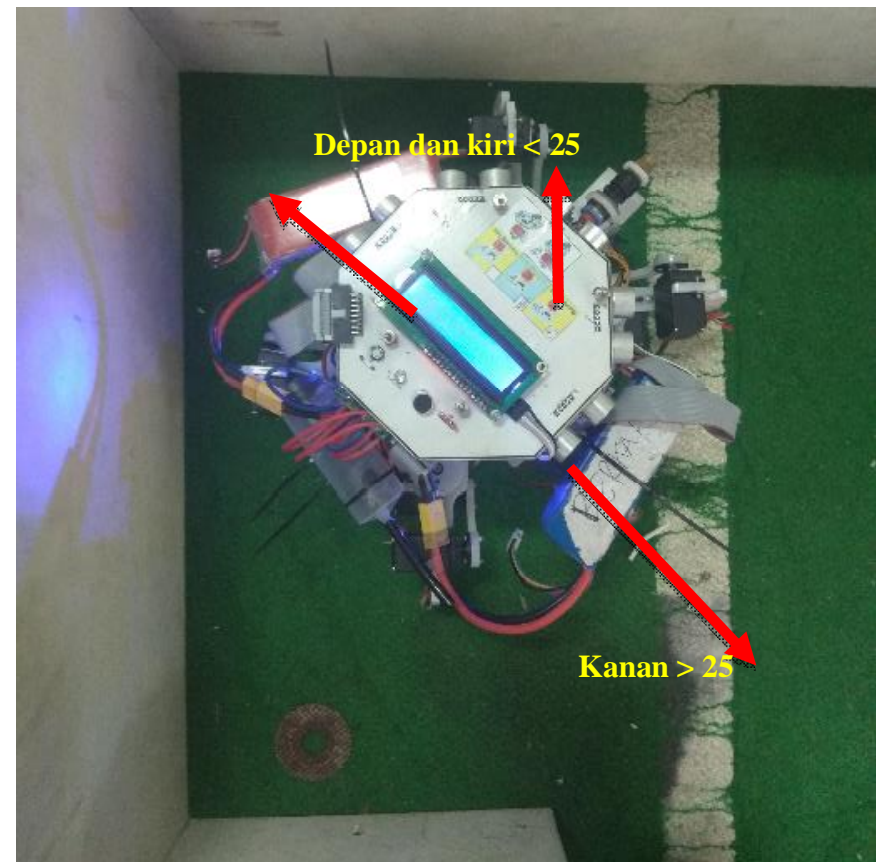

Gambar 20 Robot setelah mendeteksi halangan

\section{Pengujian dalam Mencari dan Memadamkan Api}

Saat robot menelusuri melakukan penelusuran ruangan robot pembacaan nilai dari sensor Uvtron terus dilakukan secara berkelanjutan, Sensor Uvtron akan bernilai memberikan logika High atau 1 pada saat mendeteksi adanya api. Kemudian robot akan berhenti dan berada dalam posisi standby, robot akan menyalakan indikator berupa LED yang berkedip selama 5 menit, kemudian menyalakan pompa air untuk mematikan api. Berikut adalah foto pengujian pedeteksian api pada robot.

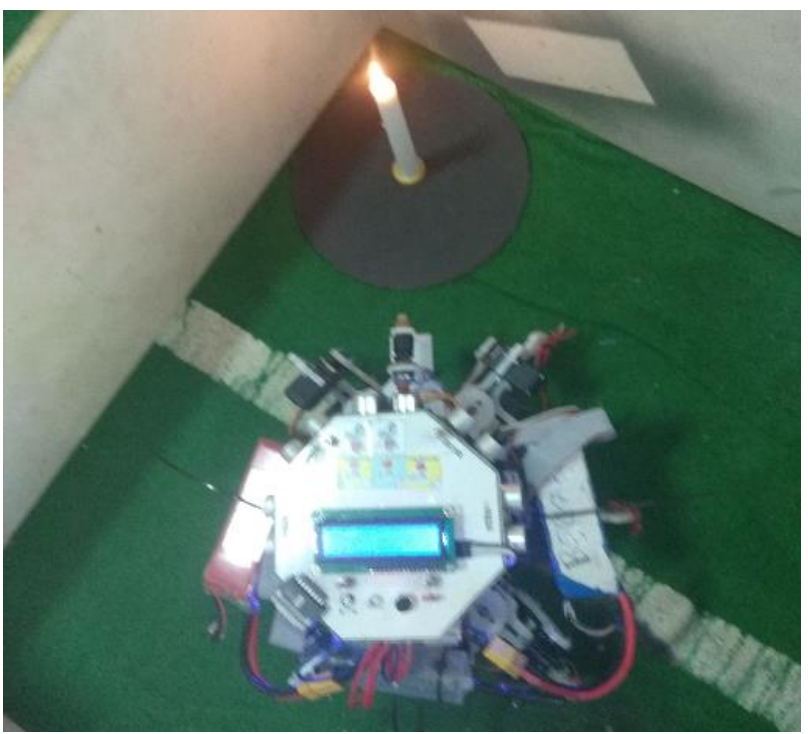

Gambar 21 Robot setelah mendeteksi adanya api

Pemadaman api dilakukan dengan air yang dipompa mengunakan mini waterpump yang memiliki supply sebesar 12 volt. Saat mendeteksi api, robot masuk ke posisi standby dan robot mulai menyalakan mini water pump, kemudian robot akan mengecek apakah api sudah padam jika masih 
terdeteksi api belum pada robot akan bergerak maju dan menyalakan pompa air lagi, hal ini dilakukan sampai robot mendeteksi api telah padam.

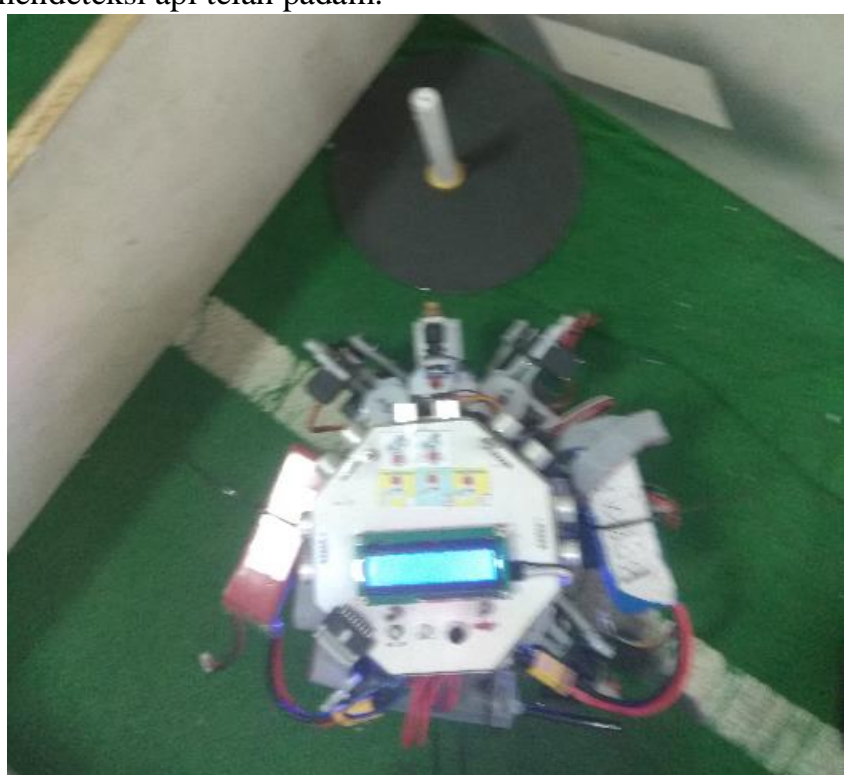

Gambar 22 Robot memadamkan api

\section{KESIMPULAN}

Dalam artikel ini telah dipaparkan rancang bangun dan hasil pengujian robot pemadam api dengan 3 derajat kebebasan. Robot Hexapod ini dibuat dengan bahan plastik akrilik. Robot ini memiliki 6 buah kaki yang masing - masing terdiri atas 3 buah motor servo, robot ini dirancang mengunakan mikrocontroller Arduino Mega 2560, Torobot Servo Controller, Sensor Ultrasonik, Sensor Uvtron, Sensor Infrared serta Motor Servo Towerpro MG995.

Pengujian robot dilakukan mengikuti panduan dari Kontes Robot Indonesia dimana robot telah mampu untuk menelusuri ruangan yang ada. Dengan algoritma wall-following robot dapat menelusuri ruangan tanpa menabrak dinding lintasan maupun rintangan lain. Robot telah dapat menemukan api serta berhasil memadamkannya.

Pengunaan sensor ultrasonik dan infrared pada robot ini telah mampu secara efektif untuk membaca jarak robot dengan rintangan. Untuk sensor Uvtron telah bekerja dengan baik dalam menemukan lokasi titik api.

\section{REFERENSI}

[1] R. N. Darmanin and M. K. Bugeja, "A Review on multi-robot systems categorised by application," in Mediterranean Conference on Control and Automation MED), Valletta, 2017.

[2] R. Bouge, "Finishing robots: a review of technologies and applications," Industrial Robot: An International Journal, vol. 36, no. 1, pp. 6-12, 2009.

[3] L. Royakkers and R. V. Est, "A literature review on new robotics: Automation from Love to War," International Journal of Social Robotics, vol. 7, no. 5, pp. 549-570, 2015.

[4] Y. Ferando, M. A. and M. A. Murshid, "Improving Productivity: A review of robotic applications in food industry," International Journal of Robotics and Technologies, vol. 4, no. 1, pp. 42-58, 2016.

[5] Aldebaran Robotics, "NAO Humanoid," Humanoid Robot Platform, France, 2012.

[6] Honda Motor, ASIMO Technical Information, Japan: Honda, 2007.

[7] M. I Dewa Gede Rai, "Rancang Bangun Robot Electronic Nose untuk

L.A. Sutawati Pengembangan Three Degree of (...) mengidentifikasi gas menggunakan multi layer perceptron," Jurnal Nasional Teknik Elektro dan Teknologi Informasi, vol. 3, no. 3, pp. 222$230,2014$.

[8] E. Guizzo, "Japan Earthquake: Robots Help Search For Survivors," Spectrum IEEE, 14 March 2011. [Online]. Available: spectrum.ieee.org. [Accessed 2017].

[9] QinetiQ, "Modular Advanced Armed Robotic System (MAARS)," QinetiQ, North America, 2008.

[10] Badan Nasional Penanggulangan Bencana, "Data dan Informasi Bencana Indonesia,” BNPB, [Online]. Available: dibi.bnpb.go.id.

[11] D. J. Pack, R. Avanzato, D. J. Ahlgreen and I. M. Verner, "Fire-fighting mobile robotics and interdisciplinary design-comparative perspectives," IEEE Transactions on Education, vol. 47, no. 3, pp. 369-376, 2004.

[12] E. Krasnov and D. Bagaey, "Conceptual analysis of fire fighting robots'control systems," in International Conference Problems of Cybernetics and Informatics PCI, Baku, 2012.

[13] K. Altaf, A. Akbar and B. Ijaz, "Design and construction of an autonomous fire fighting robot," in International Conference on Information and Emerging Technologies, Karachi, 2007.

[14] Ristekdikti, "Panduan Kontes Robot Pemadam Api Indonesia 2017," Kemristekdikti, Jakarta, 2017.

[15] Electrohouse, “32 Channels Servo Controller Manual," Electrohouse, 2011.

[16] Arduino, "Arduino Board Mega 2560," Arduino, [Online]. Available: www.arduino.com.

[17] TowerPro, "TowerPro MG995," TowerPro, [Online]. Available: www.towerpro.com.tw.

[18] D. Susilo and R. A. Nugroho, "Wall Following Algortithm," Fakultas Teknik PS Teknik Elektro dan Sistem Komputer Universitas Kristen Satya Wacana, Salatiga.

[19] T. Fincannon, L. E. Barnes, R. R. Murphy and D. L. Riddle, "Evidence of the need for social inteligence in rescue robots," in International Conference on Intelligent Robots and Systems (IROS), 2004.

[20] I. W. D. Pranata, I. B. A. Swamardika and I. N. Budiastra, "Rancang Bangun Quadrupod Robot Berbasis ATmega1280 Dengan Kaki Kembar," in CSGTEIS 2013, Bali, 2013. 
\{ Halaman ini sengaja dikosongkan\} 